\section{Microscopy CD-ROMs For Children: A Bibliography}

Caroline Schooley, Project MICRO Coordinator, MSA

Project MICRO (Microscopy In Curriculum - Research Outreach) is the Microscopy Society of America's precollege educational outreach program. Its goal isn't to recruit young microscopists; rather, MICRO uses microscopes and magnifiers to introduce scientific observation and inquiry as a way to see the world. The program is designed for middle (and upper elementary) schools, because at that level it's possible to reach all students before they must choose elective subjects in high school, and because middle school teachers often aren't prepared to teach science well, and want help.

MICRO reaches its student audience in several ways. The centerpiece of the program is a highly successful teacher's manual, Microscopic Explorations, written by professional science educators at the Lawrence Hall of Science (LHS) of the University of California at Berkeley. Microscopic Explorations is used in organized programs sponsored by MSA local societies and at least one university. Microscopic Explorations is part of the LHS GEMS (Great Explorations in Math and Science) series, and its classroom use is taught by LHS-trained "GEMS Associates" in workshops throughout the U.S. and around the world (this summer (2003), in many cities, at MSA's San Antonio meeting and even in the Philippines!). Microscopic Explorations is sold nationally in bookstores, educational catalogs and on the Internet, which makes it available almost anywhere.

MICRO supports its program with a website, www.msa.microscopy.com/ ProjectMicro/that provides a lot of information and advice that can help anyone who is interested in microscopy education. This CD listing is part of a much more extensive bibliography of books, videos, CD-ROMs, and website links available on the website. They aren't all for children in middle school; many are "adult" and are listed to help teachers, parents, and volunteers. Anyone compiling a list like this can use help. If you are aware of other relevant CDROMs, please contact the Project MICRO Coordinator, Caroline Schooley, at schooley@mon.org.

Biodisc, Inc. Enclycopedia of Biological Microslides With a 100 page, $81 / 2 \times 11$ " textbook and a complete image index, $\$ 95.00$ from Clearvue/ eav, 6465 N. Avondale Ave, Chicago, IL 60631-1996, (800)253-2788. Order $384 \mathrm{CD} 2555$ for Mac (7.1 or later) or $\$ 84 C D 2456$ for Windows. Also available directly from Biodisc, $800-453-3003$. Over 4700 plant and animal color photomicrographs make this a bargain in comparison to the cost of an equally comprehensive slide collection. Images may be moved and magnification changed, which somewhat mimics actual microscope use. So many images on one CD-ROM means limited resolution, however; pixels are obvious on full-screen images. Grades 7-12.

BioScope Initiative 2000 Cell Structure and Function $\$ 44.95$ plus shipping for a single user, $\$ 295.00$ site license (25 users), with a 63 page users manual. Order from www.ylearn.com. or (800)320-6715. Autostarts on both Mac and Windows; requires Flash software (included). The Bioscope Initiative of Purdue University has just released this $\mathrm{CD}$; it will be joined soon by similar CDs on Genetics and Microbiology. The title of this one is a bit deceptive; about half of it is "pure" microscopy, rather than cell biology. It uses a web browser format, so Internet-aware students will find it very easy to use. It's interactive and well designed, with good graphics. An active Internet connection is desirable, since there are frequent links with the BioScope website (www.bioscope.org) for supplemental information, current hotlinks, quiz answers, etc. The historical introduction to microscopy is outstanding and the how-to-do-it instructions for basic compound microscope use are clear and grade-appropriate. There is a unique, informative section that describes and compares many modern microscopies. The user can select a sample from a short list and view an actual image of it as seen with each of the microscopes. The cell biology is good, too, including a clever "build a cell" sequence. The medical topics must have been chosen by teenagers or someone who knows them well; the microbiology of pimples is included! Good quizzes can be used for review or test. Grades 9-14. RECOMMENDED

Carlson, S., editor 2000 The Complete Collection of the Amateur Scientist on CD-ROM About $\$ 35$ from software retailers. Published by the Tinker's Guild, Menlo Park, CA 94025, www.tinkersguild com. For Mac or Windows. Requires a Web browser, Netscape 4.0 is recommended. The Amateur Scientist was a popular monthly column in the old-format Scientific American magazine. This CD-ROM version, edited by one of the last contributors to the old column, is better than a print collection of the old articles, sllue un иाe CD they're indexed and rated for safety and current relevance. There are over 1000 projects, making it a gold mine for science fair participants. There are both chronological and topical indexes. Although there is a "microscopy" category, it contains less than a dozen adult-level articles. Adult.

Carolina Biological 2000 Neo-Slide Collection $\$ 59.95$ each or $\$ 379.95$ for all seven. Purchase from Carolina Biological, $800-334-5551$ or WwW.carolina.com; requires Windows 95, Mac 7.5, 16 MB RAM, or better. The teacher who is doing "wet" microscopy still needs prepared slides for many topics, and they're expensive. These CDs provide a usable substitute at moderate cost, although one of the CD-ROM atlases might be a better investment for a comprehensive survey of animal tissues; the $C D$ in this series selected for review had just 50 images. The text accompanying each image is well written and informative, and a brief multiple-choice quiz is avallable with each. Magnification change and measurement are possible. Titles are BA-40-1308A Viruses and Bacteria, BA-40-8792A, Protozan Diversity, BA40-8766A Algal Diversity, BA-40-1342A Fungi Diversity, BA-40-1350 Plant Diversity, BA-40-1060A Animal Cells and Tissues, and BA-39-1130 Human Disease. Grades 6-14.

Clearvue/eav 1998 How to Use the Compound Microscope \$75.00; from the publisher at 800-253-2788; 6465 N. Avondale Ave., Chicago, 1160631 1996. Requires Mac $(68040)$ or Windows 3.1 or 95 . The $C D$ adds the teaching amenities that CDs do so well: editing and report writing, multiple choice tests, and individual student records. Instructions on the use of a compound microscope are clear and well illustrated. The advice on the use of a substage condenser may be a bit too simple (move it to adjust image brightness), but most middle school microscopes dorit have condensers. Poor advice is given on the use of oil immersion objectives. A major error in the original video is repeated; benzene or ether are suggested to clean lenses. Ether is very flammable, and benzene is a biohazard; neither has any place in a middle school science lab. Half of the CD content is a survey of microorganisms, and there is good advice on preparation of hay infusions and wet mount slides. High school.

Clearvue/eav Microscopic Anatomy $\$ 110.00$ from Clearvue/eav; order \#84CD 2589; for either Mac (7.0) or Windows. This is a less comprehensive collection than Biodisc/Clearvue's Encyclopedia of Biological Microslides there are 1200 mammalian images. It does include electron micrographs, plus nearly 2000 test questions. If this CD is too expensive, a good atlas is available on the Web athttp://wWw.udel.edu/Biology/Wags/histopage/histopage.htm Grades $10-12$ and adult.

Corel Corporation Corel Professional Photos About \$25.00 per CDROM; contact Corel, 1600 Carling Ave. Ottowa, Ontario K1Z 8R7, Ganada, phone (613)728-8200 or FAX (613)761-9176 for the names of retail dealers. For both Mac and Windows. Copyable professional stock photos are an excellent source of high quality images for classroom use. Corel has hundreds of titles; two relevant ones (each with 100 images) are \#645000, Microscopic Images (colorized SEMs of biological subjects) and $\$ 610000$. Sand Grains of the World (stunning images of shell, gemstone, and other mineral sands) Adult.

Corel CD Home 1997 Beyond the Naked Eye $\$ 32.95$ from the Edutainment Catalog as item \#353049, call $800-338-3844$; or other retail sources For DOS, Win 3.1, and Mac; installs easily. Corel's three-part Life Science Mystery series begins on this CD with the microscopic world of bacteria and viruses. Two situations are presented to the student-scientist: diagnosis of a bacterial disease and creation of an AIDS-awareness program. There's a lab in the research center, with an incubator (for the bacteria), light and scanning electron microscopes, and a harassed technician. The microscopes are used effectively, but the emphasis is on microbiology; scientific method is presented well. The small-world adventure continues in the second CD, The Green Files (not reviewed) and concludes with Crisis at the Anamalia Research Center. The reviewed CD is similar to Science Sleuths (see below), but for somewhat older students; grades 8-12.

Cubic Science, Inc. 1997 Virtual Physics \$34.95; from Cubic at 800-383-6363 or \#712001 from The Edutainment Catalog, P.O. Box 21210 , Boulder, CO $80308 ; 800-338-3844$. Minimum system: Windows95 or 3.1 (Pentium 75) or Mac (68040) with 12MB. Waves, light, mirrors, and lenses are among the experimental topics covered with animated tutorials, movies (very low resolution), and review problems. There is a simple "space aliens 
Ineed some advice in order to optimize the carbon coating process of my replicas for TEM. Alessandro Mattozzi <alessandro@polymer kth.se>

We can share our optimized conditions for carbon coating. The carbon rod which we use is about $1 / 4^{n}$ in diameter. We sharpen one end (about $1 / 4^{11}$ length) of rod to $1 / 8^{\prime \prime}$ in diameter. In our experience, the vacuum in the evaporating chamber is the most important parameter for making the high quality carbon films. A higher vacuum is better. Normally, we use $1.5 \times 10^{-6}$ torr. The best current value is really dependent on the vacuum which you use. Lower vacuums need a lower current to get sufficient speed of carbon film growth; higher vacuums need a higher current value. However, the carbon film made under low vacuum is easily oxidized and the film is very soft and prone to breaking. Another tip is that the speed for growing the carbon film is related to the current value. However, the maximum current for growing a high quality carbon film is limited by the value that will cause you to see a spark coming from the filament. The spark is a large group of carbon molecules which will mess up your carbon film. Wendy Zhang <wendy@grid-tech.coms

I agree with Wendy Zhang: A better vacuum results in a better carbon film quality. But, using Electron Gun evaporation in combination with good vacuum delivers an even better result. The carbon must be well dispersed to produce a fine, uniform and stable film. Thermal evaporation is not an effective method to produce mono atomic vapors. It's more like clouds of 10-15+ atom clusters. Electron beam evaporation utilizes bombardment of carbon by accelerated electrons. This method is more effective in forming nearly mono atomic carbon "clouds" and therefore better carbon film homogeneity/uniformity. This process also may be better controlled than thermal evaporation. Finally, you may produce very thin, uniform and stable films. Personally, I am using 1.2-1.5 $\mathrm{nm}$ thick films for routine work in shadowing and negative staining. Sergey Ryazantsev <sryazant@ucla.edu>

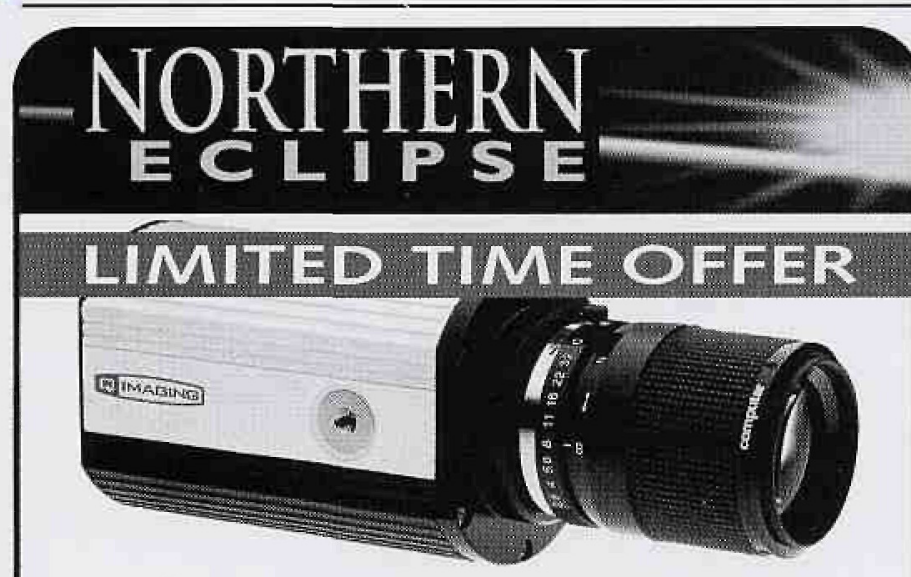

Get the power of Northern Eclipse 6.0 FREE by ordering a Qlmaging FireWire CCD camera When you buy a QImaging CCD FireWire camera directly from us at the manufacturer's suggested list price, we will include, for a limited time, one FREE Northern Eclipse 6.0 application of your choice. Applications such as Brightness/ Time, Time-Lapse, Image Merging, Fast Capture to Ram, and even De-convolution are available. See the On Sale page of our web site for a full list of applications available with this offer.

www.empix.com

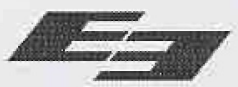

E M P I X

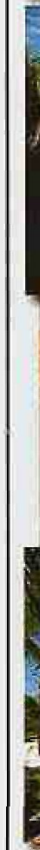
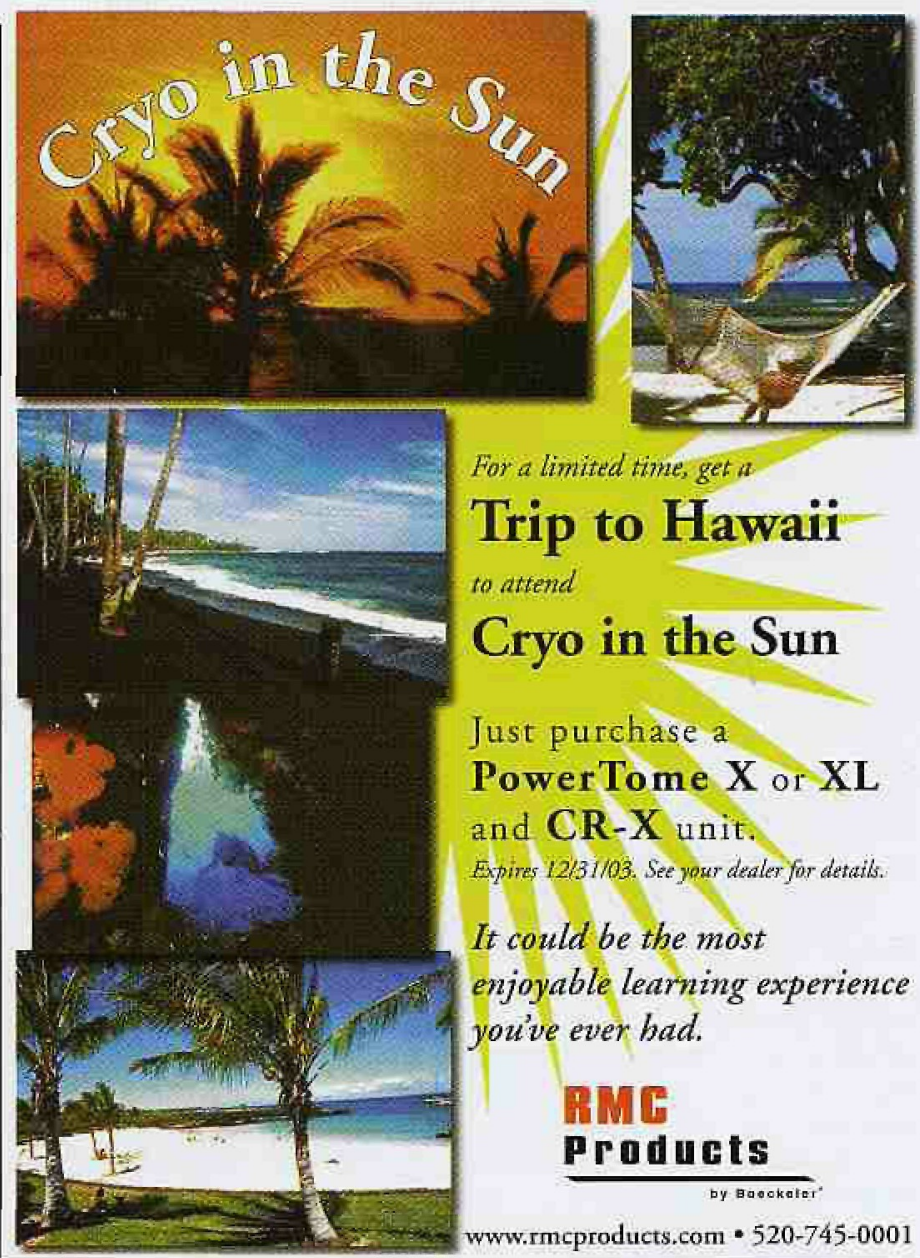

For a limited time, get $a$

Trip to Hawaii

to attend

Cryo in the Sun

Just purchase a

PowerTome X or XL

and CR-X unit.

Expires $12131 / 03$. See your dealer for detatls.

It could be the most

enjoyable learning experience

you've ever had.

\section{RME \\ Products}

www.rmcproducts.com $-520-745-0001$

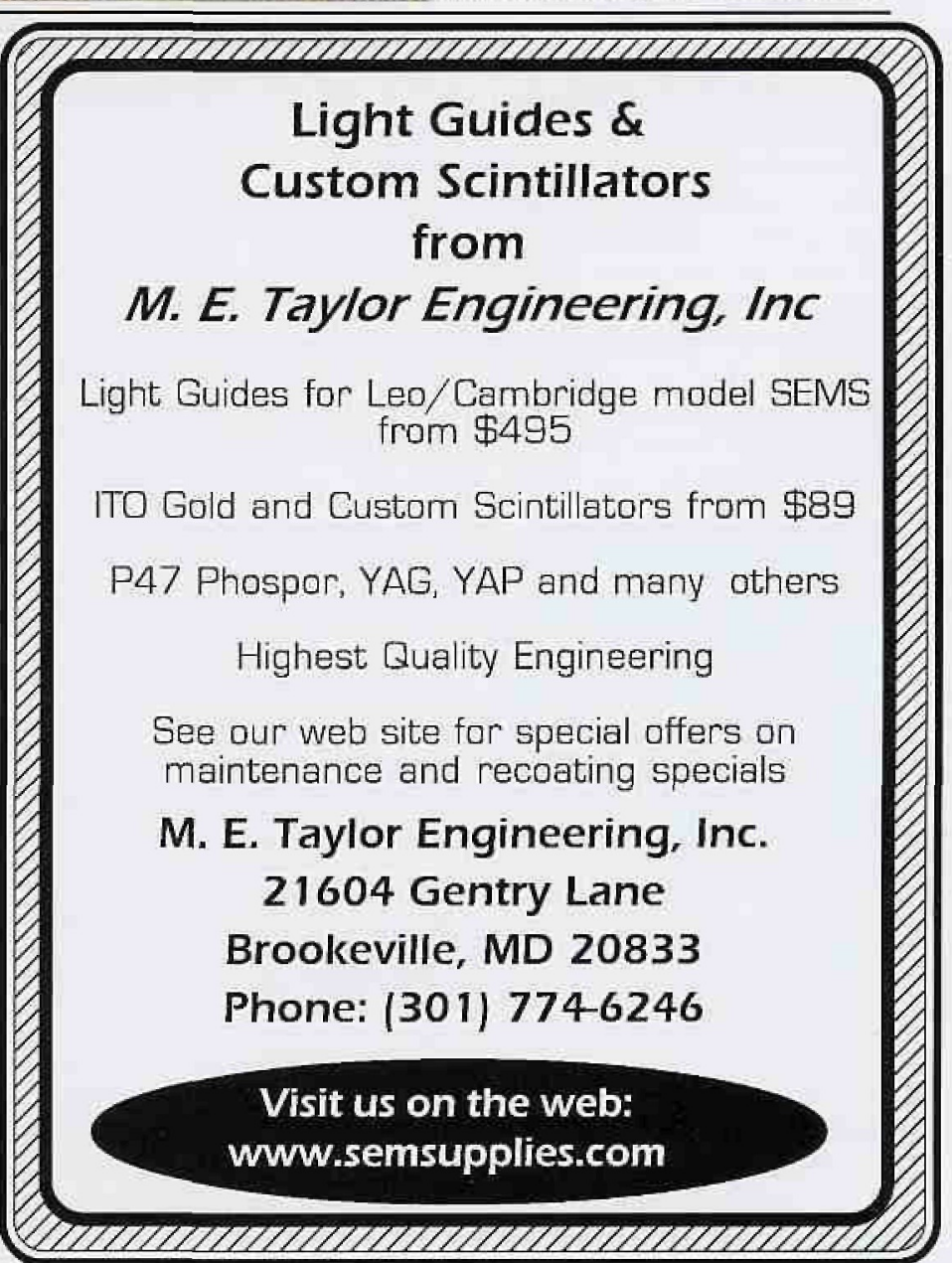


game which must be followed to access the various topics; lenses are reached via wave theory and refraction, which is good. Information is available on the web at www.virtualphysics.com/vpedutco.htm. For grades 6-9; the game is lower level, but the math is high school materiel

Digital Imaging Associates 1995 Microscopy $\$ 65.00$ for tem \#Z4CD2360 from Clearvueleav, 6465 N. Avondale, Chicago, IL 60631-1909; 800-253-2788. Requires Mac II or better with HyperCard 2.1 or HyperCard Player; no IBM version. This is a microscope users' manual that emphasizes written instruction; interaction is limited to selection of still images (e.g. microscope parts) and an occasional film clip. Since this manual can be usermodified (with PEAK software), it might be useful for someone creating a lab manual. High school-adult.

Discovery Multimedia 1998 The Histology CD $\$ 16.00$; published by the Biology Dept., San Diego State University, San Diego, CA 92182-4614 619-594-5415. For Power Mac OS 7.0 or better), Windows 95/NT, or UNIX.A good CD should be both fast and interactive; this one is neither. The 175 images (140 light micrographs, 35 SEMs) are organized by organ systems, but there is no comprehensive index. The CD works within Netscape 3.0 (included) or other recent browsers. This limits the useful image size, requiring lots of scrolling. So although its low price is tempting, it wor't help a precollege teacher. It DOES have an outstanding advantage for the college instructor who wants to teach morphometric analysis, because the images are linked to problem sets that use the program NiH Image (included for Mac) for measurement. Adult.

Eames Office 1999 Powers of 10 Interactive $\$ 79$ from either the Eames Office, 2665 Main St., Santa Monica, CA 90405, 310-396-5991, www.eamesoffice.com, or www.powersof10.com. For Mac or Windows; requires QuickTime 2.1 .2 or better. The latest in the series of Powers of 10 variants (film, video, DVD, book, flipbook) is a complex, interactive CD. It goes far beyond the sequence of sizes that are brilliantly presented by its predecessors (and are available on this CD), extending the mathematical concept into time. People involved, the tools that they use, the places that they work, the things that they study, etc. are presented in an interwoven, interactive format A sampling of the CD is available at www. powersof $10 . \mathrm{com}$. It's too complex fo: a beginning microscopist in elementary or middle school, but the other formats are RECOMMENDED for those grades. Fascinating for high school-adult

Edmark Corp. 1998 Zapl \$29.95, with a 50 page users' manual from Edmark at PO Box 97201, Redmond, WA 98073-9721, 800-320-8379 www.edmark.com. For Macintosh or Windows 3.1 or 95 . Subtitled "Save the show with sound, light, and electricity", this CD-ROM is sure to capture the interest of a computer game-addicted middle schooler. All three topics are introduced in game format, complete with levels of complexity. In the optics section, laser beams are aimed with mirrors, lenses, prisms, and filters; the targets are eggs that hatch into cute monsters when activated by the beam. It actually does a very good lob of teaching reflection, refraction, absorption, and color It's much too time consuming to use in the classroom, but would be a delight for home use. There is ample reference material, and homeschool parents can set options to control complexity. Middle school. RECOMMENDED

Excalibur Mineral Company 1999 Photographic Guide to Mineral Species $\$ 69.95+\$ 4.00$ shipping from Excalibur at 1000 North Division Street Peekskill, NY 10566, www.bestweb.net/ excalmin. For Windows or Mac requires Netscape Communicator (included). This is an "adult" CD, but the superb photos make it an excellent visual supplement for a student who is learning about crystals and other minerals. It's truly a "coffee table book" on a CD with an unbelievable 5400 photos, which search and load rapidly in Netscape (and not at all in Internet Explorer). There is an eye-catching 300 image automatic slide show which can be set to play continuously. Images can be searched by location or mineral content. Descriptions are minimal; it isn't intended as a textbook substitute. Adult. RECOMMENDED

Griffen, B.J. 1995 The Virtual SEM, $1.3 \$ 30$ US (bank draft) from B.J. Griffen, Centre for Microscopy and Microanalysis, University of Western Australia, Nedlands, Perth, W.A., Australia 6907; Email bjg@cyllene.uwa.edu.au. It's public domain software and can be downloaded from the Internet at ftp: www/l.amc.anl.gov. Although this CD-ROM is intended as a college-level teaching aid for beginning scanning electron microscopists, it has exciting potential as a supplement for interested middle and high school students. There's enough information in the tutorial to enable a student to use an onscreen SEM control panel. The successful operator can select a specimen opal, a housefly, and a plant stem are available in version 1.2. Magnification, focus, contrast, and brightness are all controllable; it's a realistic simulation. Grades $8-12$ and adult.

Leica Microsystems 2000 Discover the Microscope $\$ 89.00$ from several sources; call Leica Customer Service at (800)248-0123, ext. 1, for a list of dealers For Mac or Windows. This CD is subtitled "a complete multimedia introduction for students", and it fills that promise well, with first-rate photography (by Bruce Russell) and animation.. It's easy to use and suitable for high school or introductory college biology classes; parts probably can be used with advanced middle school students. An interactive "virtual" microscope teaches slide manipulation and magnification. The descriptions and demonstrations of imaging modes and slide making methods are outstanding. There's excellent text throughout (by Ken Rainis), including detailed, printable instructions for both student and teacher for the exercises presented. It's definitely RECOMMENDED. High school - adult.

Michigan State University, Communication Technology Lab and Center for Microbial Ecology 1996-97 Microbe Zoo Issued by Peregrine Publishers and available for $\$ 34.98$ as \#80540 from The PC Zone, 800-258-2088, or The Mac Zone, $800-248-0800$. Runs on Mac or Windows. The Microbe Zoo presents 140 organisms in excellent full-screen micrographs (LM, TEM, and SEM; all are monochrome). It invites young people to actively explore the world of microbes; most are bacteria, plus some fungi, protists, and multicellular organisms. Learners select "microbe zoo" habitats such as dirt, water, and inside of humans and animals. At the "Snack Shop," for example, you can look at the microbes that live in snack foods. Within each habitat, students zoom down to see the microbe. The "Size Machine" presents both measurements and relative size well; it and other animations aren't "cute" and won't irritate older students. Text and audio are informative, and there are four good lesson plans. There is a searchable database and report-writing capability. Apreview is available at http://commtechlab.msu.edu/ctiprojects/dlc-me/ For grades 5-7; usable in high school. RECOMMENDED

Microscopy-UK 1997 (revised) Microscopy for the PC Available for 24.95 pounds from Microscopy UK at http:/WwW.microscopy-uk.org. uk/sell/ collist.html . For PC only; no Mac. A "virtual microscope" is presented as a control panel that permits adjustment of many parameters. There are many slide sets (all but one are biological) supplemented with a library of images, quicktime movies, and articles selected from the popular English amateur microscopy website. The CD-ROM has won awards in England, and the "virtual microscope" itself can be downloaded free at http:/www.microscopy-uk.org.uk/ prodir/software/softmol.html. Not yet reviewed.. High school - adult.

Microscopy-UK 2000 Slide-making CD Available for 26.50 pounds from Microscopy UK at hitp://www.microscopy-uk.org.uk/sel//cdlist.html. For PC only; no Mac. "How to prepare, mount and ring fluid mount slides using NBS aqueous mountant". Not yet reviewed.

Mona Group LLC 1998 Understand! Biology: Molecules, Cells, and Genes. $\$ 29.95$; ISBN 0-9659432-1-6 From The Mona Group, P.O. Box 407, Sunderland, MA 01375-0407; 413-548-3955; sales@monagroup.com. For Mac and Windows. Those who teach cell biology will shout with joy when they look at this CD. It's listed here because it includes 17 video microscopy sequences plus 125 micrographs (LM and EM) that present the best modern microscopy of protists, cells in culture, organelles, etc.. Most content is college level, but the middle schooler who wants to see what Paramecium really looks like up close, for example, should be thrilled with the images. High school teachers will be able to use the fine drawings and animations of cell structure. The basic $\mathrm{CD}$ is a real bargain. An "Instructor's Version" is available, for $\$ 69.95$; with it teachers can assemble a full-screen "slide show" of selected images. High school - adult. RECOMMENDED

Neo/Sci Corporation 2000 Exploring with a Microscope $\$ 99.95$ Purchase from Neo/Sci, P.O. Box 22729, Rochester, NY 14692-2729, 800-526-6689, www.neosci.com or Carolina Blological, 800-334-5551, www.carolina.com; requires $16 \mathrm{MB}$ RAM, Windows 95 or Mac 7.5 , or better. Basic microscopy is introduced on this CD with brief but well-written text (by Ken Rainis, co-author of the outstanding Guide to Microlife) and animation. The slide collection contains just 14 images, but they're excellent micrographs of microorganisms, simple invertebrates, and plants. The best segment is a series of animations showing how to do various important specimen preparation methods: hanging drop slides, wet whole mounts, bacterial smears and stains, squash preparations, and hand-microtome sections; this information isn't duplicated in any of the other videos and CDs reviewed here. Suggestions 
for further investigations follow a useful quiz format. The extensive dictionary will help a middle school student use this $C D$, but it's probably better for high school. A 17 page teachers' guide and 26 pages of copyable student worksheets ship with the $C D$; they provide a complete framework for classroom use. Grades 6-12. RECOMMENDED

Neo/Scl Microscopy $\$ 100$ from Interactive Teachers, 20 Drake Lane, Oakland CA $94611-2613,888-232-6133$, hschott@aol.com, or directly from NeoSci at www.neosci.com.. For Windows only. "Includes an animated explanation of the physics of microscopy." Not yet reviewed.

Neo/Sci Animal Cells and Tissues $\$ 60$ from Interactive Teachers, 20 Drake Lane, Oakland CA 94611-2613, 888-232-6133, hschott@aol.com, or directly from NeoSci at www.neosci.com.. For Mac and Windows. "Provides a virtual library of interactive slide images supported by text and video clips." Not yet reviewed.

Neo/Sci Common Things Neo/SLIDE \$100 from Interactive Teachers, 20 Drake Lane, Oakland CA 94611-2613,888-232-6133, hschott@aol.com, or directly from NeoSci at www.neosci.com.. For Mac and Windows. "Comprehensive set of nearly 50 digital slide images of insects, microorganisms and other things." A companion five microscope slide set is available from $\mathrm{Neo} / \mathrm{Sc}$ at www.neosci.com. Not yet reviewed.

Neo/Sci Five Kingdoms Neo/SLIDE \$60 from Interactive Teachers, 20 Drake Lane, Oakland CA 94611-2613,888-232-6133, hschott@aol.com, or directly from NeoSci at www.neosci.com. For Mac and Windows. Ten interactive microscope images are provided for each of the five kingdoms. There are video clips of Paramecium, Euglena, Daphnia, Hydra, and Planaria. Substantial text supports lecture, tutorial, or assessment use. Other CDs in the same series provide detail on each kingdom: Viruses \& Bacteria, Fungal Diversity, Algal Diversity, Protozoan Diversity, and Plant Diversity. Not yet reviewed.

$\mathrm{Neo} / \mathrm{Scl}$ A Closer look at Pond Life $\$ 80$ from Interactive Teachers, 20 Drake Lane, Oakland CA 94611-2613, 888-232-6133, hschott@aol.com, or directly from NeoSci at wWw. neosci.com.. For Mac and Windows.A "virtual enclyclopedia on pondlife and the environment", with a large image collection, reference text, video clips, and suggestions on collecting and observation. Not yet reviewed.

Neuronware 1997 Scopemaster Neuronware, 15 Madison Ave, Toronto, Ontario M5R 2F2, Canada. For Mac or Windows. $\$ 70$ - $\$ 75$ from 3 U.S. sources: Clearvue, 800-253-2788, Flinn Scientific, 800-452-1261, and Sargent Welch, 800-727-4368. An interactive microscope teaches the use of the controls of a compound microscope: The user can select three objectives, adjust the substage diaphragm, and use coarse and fine focus. Advice on microscope use appears if a mistake is made. Slides must be centered on the stage in a realistic way that makes the inverted image of the compound microscope understandable; it will be nonthreatening, nondestructive practice for a beginner. Ten sets of nine slides each (mostly biological) are included, each with its own well-written reference book; the goal is specimen identification. The images are good color light micrographs; each can be viewed full-screen after the microscope is in focus, or all can be reviewed quickly in "teacher" mode. There is a self-test, and a printable test for class use. More information (and a downloadable update for Windows) is available on the web at www.snap.ca/ neuronware/index.htm. Middle and high school. RECOMMENDED

Pagliaro, I, Murray, C, Curran, G., Orkand, A, and Astion, M. 1997 Microscopy-Tutor. ISBN 0-7817-1217-3 $\$ 195.00$ plus shipping; distributed by Lippincott-Raven Publishers, 12105 Insurance Way, Hagerstown, MD 21740 , $800-638-3030$. For Macintosh and Windows 3.1 or 95/NT; easy installation. Developed by the Department of Laboratory Medicine and the Center for Bioengineering at the University of Washington, Seattle, this is a college-level introduction to the use of a research-quality compound microscope. Its extensive use of QuickTime animation to illustrate alignment steps and optical principles make it much more than a "book on a CD"; moving ripples on a pond really do make it easier to understand wave theory! Kohler illumination is emphasized and explained. Most, but not all, terminology is defined; a glossary would help beginners. Proper care of lenses is covered well, but there's no instruction on how to use immersion oil properly. There is a brief concluding self-test that is more of a review of important information than a quiz. Adult.

Queensland University of Technology 2000 Microscopy $\$ 99.95$ Purchase from Knowledge Books and Software, 800-600-2545 (in Australia,
1-800-773393) www.kbs.com.au, Neo/Sol P.O. Box 22729, Rochester, NY 14692-2729, 800-526-6689, www.neosci.com or Carolina Biological, 800-334 5551, www.carolina.com, or Clearvueleav, 800-253-2788, www.clearvue.com. For Windows 3.1 or higher; no Mac version. The interactive capabilities of the CD-ROM format are used well to present an introduction to the fundamentals of both light and electron microscopy. Almost all of the "modern microscopies" are described briefly but clearly; the only major exception is scanning tunneling/ atomic force microscopy. Excellent micrographs make it easy to compare the visual effects of the various imaging methods. Video clips present microscope use and preparation methods; animation is used for the physics of microscope optics. There's an extensive tutorial, assessment, and a good image gallery. Use of this CD could greatly enhance the understanding of textbook images by high school and college students. Grades 9-14. RECOMMENDED

Schoolhouse Interactive 1995 Get Up Close Published by Schoolhouse Interactive, Inc. Lake Road, Charlotte, VT 05445. \$44.95 from Williamson Publishing Co., 800-234-8791. Microscopes and telescopes share this CDROM, which is written for either Mac or Windows. It's animated, Interactive, and accurate. Games and quizzes are used to reinforce, and many good light and electron micrographs (including stereol) can be selected. The target audience isn't clear; although the quizzes and experiments are middle school level, Dr. Ole Mole's cartoon antics will appeal to a lower grade level. Elementary school?

ScienceWorks 1999 SlideWorks Beginner Slides \$29.95 + shipping, from Carolina Biological Supply, PO Box 6000, Burlington, NC 27216-6000 800-334-5551 as \#398713, or directly from ScienceWorks, 808 Retford Circle, Winston-Salem, NC, 800-478-8476. For Mac or Windows; hard drive installation recommended. 45 common specimens (microorganisms, various cells, thread, kitchen spices and crystals, newsprint, etc.) can be moved from a slide box to a microscope stage, focused, and viewed at three magnifications in a realistic manner. Good quality full-screen images can be selected, and a student can draw an image, take notes, and print the result. Regrettably, it isn't possible to move the slide on the stage, which can teach a beginner how to manipulate the inverted image of a compound scope. There are quizzes, simple games, a pronouncing glossary with both simple and complex terms, and a link to the Scienceworks website, www.scienceclass.com, which has supplemental educational content. Probably middle school. Sullivan, J. 1999

Cells Alive $\$ 80$, works on both Windows \& Mac; requires an internet browser (Netscape or equivalent). Produced by Quill Graphics, 568 Taylor's Gap Road, Charlottesville, VA 22903, (804) 296-8994; order from www.cellsalive.com or Yahoo at http://st13.yahoo.net/cellsalive/ The images from the outstanding Cells Alive website ( $w$ ww. cellsalive.com/) have been made available in both VHS video and CD-ROM formats, which will greatly increase their classroom usefulness. Nevertheless, the micrographs, drawings, text, and excellent film clips of a variety of living, moving cells and microorganisms will make it a valuable supplement to textbook content. Middle school - adult. RECOMMENDED

Vazzana, J. 1995 Microscope - Nature Explorer. The Mac (7.0 or better) version is avallable now (inquire about Windows) for $\$ 69.00$ plus shipping from Orange Cherry/New Media Schoolhouse, P.O. Box 390, Pound Ridge, NY $10576 ; 914-764-4104$ or 800-672-6002. Professor Scope introduces light and electron microscopes in the Nature Center; the menu then offers 34 objects to view grouped in the categories Air, Grass/trees, Pond, and Rocks. Each object requires mouse "focusing" and is accompanied by written and voice text. There's a good concept here; unfortunately, the execution has problems. Most of the objects are line drawings, not micrographs, and there is no magnification information. Much of the text is simple and informative, but some of the "simplification" is confusing or inaccurate. Age $9 \&$ up.

Videodiscovery, Inc. 1995 Science Sleuths, Volumes $1 \& 2$ For Macintosh 7.1 or Windows 3.1. $\$ 79.00$ each or $\$ 149.00$ for both, with teacher's manual and assessment software on 3.5 inch disk. Science Sleuths is an award-winning series of mysteries for middle school students. Designed to build critical-thinking and problem-solving skills, the series challenges students to solve real-world problems by researching clues and conducting science experiments using interactive tools. Each volume contains two mysteries, each with 6 solutions of increasing difficulty. One mystery in each volume provides a microscope as one of the investigative tools; although use of magnification is extremely limited, these CDs are great inquiry science. Grades 5-9. 